hydrochloric acid which readily liberates hydrogen sulphide from zine sulphide.

This statement brings out very clearly the absurdity of the position of those who accept the humic acid theory. These humic acids are supposed to be strong enough and soluble enough to liberate hydrochloric acid from calcium chloride, but not strong enough or soluble enough to liberate hydrogen sulphide from zinc sulphide. It is also suggested that this method be made the basis for a quantitative determination of the lime requirement of the soil. The writer does not believe this possible because he has shown that acid soils do not adsorb equivalent amounts of different ions. A determination of the amount of zinc adsorbed by the soil will not tell us the amount of lime to be applied to the soil. Furthermore it is not possible to use a factor to determine the amount of lime to be used from the quantity of hydrogen sulphide given off, because it has been found that the ratio of the amounts of two different ions adsorbed will vary with the character of the soil used. The ratio of the amount of zine adsorbed to that of calcium will vary with each different sample of soil depending upon the kind of colloidal matter present. The only sure way to determine the lime requirement of an acid soil is to use the same material in the test as is used in the field for correcting the acidity. This is done in the methods of Veitch and Süchting.

As to the qualitative methods for the detection of soil acidity, it has been found that all kinds of litmus paper are not suitable. In fact, in the chemical laboratory of the Michigan Agricultural Experiment Station, Kahlbaum's litmus paper has been found to be the only one not so thoroughly saturated with alkali as to make it unsuitable for this purpose. This litmus paper is so sensitive that it is necessary to leave it in contact with the soil particles only for a moment or two. In this way it has been found that soils only very slightly acid give a distinct test.

\section{J. E. Harris}

DIVISION OF CHEMISTRY,

\section{Michigan Experiment Station}

4 Loc. cit.

\section{A SUGGESTION IN CONNECTION WITH THE STARK-ELECTRIC EFFECT}

THe discovery last year of the separation of certain spectrum lines when emitted in an electric field has been followed by a remarkably thorough investigation of the phenomenon by Stark and his co-workers. ${ }^{1}$ Hydrogen, helium, lithium, calcium, sodium, magnesium, aluminium, thallium and mercury lines have been examined; but only the diffuse, subordinate series lines of hydrogen, helium and lithium show a separation as great as an angstrom for a field intensity of 10,000 volts per $\mathrm{cm}$. The Stark-electric effect differs from the Zeeman effect in that the various lines of the same series are not equally affected, but, for the same field, the separation increases with the number of the term. Stark empha-

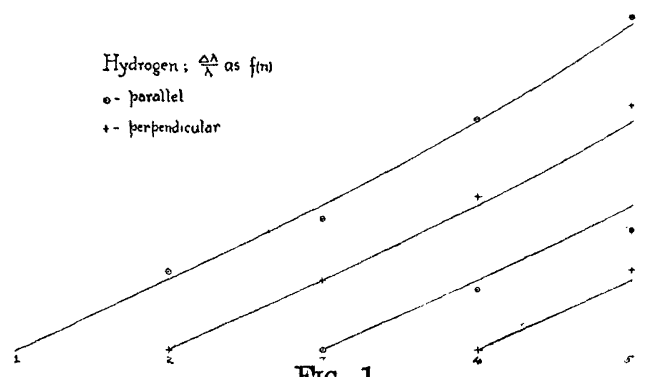

Fig. 1.

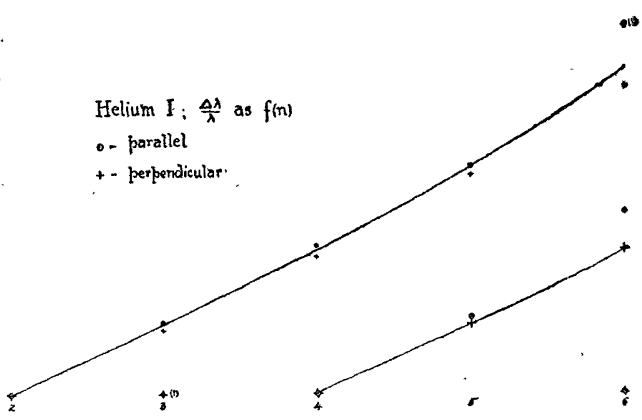

FIG. 2.

sizes the complexity of the effect, and gives no law for the relative separation of various lines of the same series, though he suggests that a relation should be sought between the relative change of frequency of the various lines and their term numbers. ${ }^{2}$

\footnotetext{
1 Annalen der Physik, 43, 965-1047, 1914.

2 L. c., p. 1033.
} 
From an examination of the data it seems probable to me that the effect is simpler than Stark implies, and that such a relation as he suggests does exist. The relative change of frequency $\Delta n / n$ is equal to $\Delta \lambda / \lambda$, the separation of corresponding, symmetrically placed components divided by the wave-length of the particular line. If we plot this $\Delta \lambda / \lambda$ as a function of the term number, smooth curves drawn through the points are found to agree closely in slope, etc., differing only in the number of the term, at which they start. Figs. 1 and 2 show the results for hydrogen and helium I. The numerical data are given in the following table. The numbers in brackets are the term numbers.

$10^{3} \times \Delta \lambda / \lambda$ FOR A FIELD OF 28,500 VOLTS PER CM.

\begin{tabular}{|c|c|c|c|c|c|}
\hline $\begin{array}{c}\text { Compo- } \\
\text { nents }\end{array}$ & Polarization & $\mathrm{H}$ & $\mathrm{HeI}$ & HeII & Calc. \\
\hline $\begin{array}{l}\text { Outer } \\
\text { Outer } \\
\text { Outer } \\
\text { Outer }\end{array}$ & $\begin{array}{l}\text { Parallel } \\
\text { Parallel } \\
\text { Parallel } \\
\text { Parallel }\end{array}$ & $\begin{array}{|ll|}(2) & 1.00 \\
(3) & 1.68 \\
(4) & 2.98 \\
(5) & 4.31\end{array}$ & $\begin{array}{l}\text { (3) } 0.93 \\
\text { (4) } 1.91 \\
\text { (5) } 2.96 \\
\text { (6) } 4.77(?)\end{array}$ & $\begin{array}{c}\text { (3) } 1.05 \\
\text { (4) } 2.07 \\
- \\
-\end{array}$ & $\begin{array}{l}0.90 \\
1.86 \\
2.94 \\
4.20\end{array}$ \\
\hline $\begin{array}{l}\text { Outer } \\
\text { Outer } \\
\text { Onter }\end{array}$ & $\begin{array}{l}\text { Perpendicular } \\
\text { Perpendicular } \\
\text { Perpendicular }\end{array}$ & 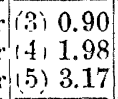 & $\begin{array}{l}\text { (3) } 0.83 \\
(4) 1.77 \\
(5) 2.82\end{array}$ & $\begin{array}{l}\text { (3) } 0.93 \\
\text { (4) } 1.85 \\
\end{array}$ & $\begin{array}{l}0.90 \\
1.86 \\
2.94\end{array}$ \\
\hline $\begin{array}{l}\text { Inner } \\
\text { Inner }\end{array}$ & $\begin{array}{l}\text { Parallel } \\
\text { Parallel }\end{array}$ & $\begin{array}{ll}(4) & 0.79 \\
(5) & 1.55\end{array}$ & $\begin{array}{l}\text { (5) } 1.00 \\
\text { (6) } 2.36\end{array}$ & - & $\begin{array}{l}0.90 \\
1.86\end{array}$ \\
\hline Inner & Perpendicular & (5) 1.04 & (5) 0.91 & - & 0.90 \\
\hline
\end{tabular}

Hydrogen differs from the other elements in that the components polarized parallel to the field, and those polarized perpendicular to it lie on different curves.

The smooth curves shown in the figures all correspond to the equation

$$
\frac{\Delta \lambda}{\lambda} \times 10^{3}=0.89(n-p)+0.01(n-p)^{3},
$$

where $p$ is the number of the term where the curve begins in each case.

These constants refer to a field of 28,500 volts per cm. Assuming the separation to be proportional to the field, which Stark proved to be true for the hydrogen series, the equation may be written

$$
\frac{\Delta \lambda}{\lambda \mathrm{E}} \times 10^{8}=3.1(n-p)+.035(n-p)^{3},
$$

where $E$ is expressed in volts per cm.

The reduced separations, $\Delta \lambda / \lambda$, of the HeI lines agree quite closely with this equation; the deviations in the case of the hydrogen lines are larger, but both positive and negative. Curves given by Stark for the variation of the separation with the field strength ${ }^{3}$ seem to show a greater accuracy for his measurements than these deviations would imply. Yet a simple curve can not be drawn through the points representing the outer components of the hydrogen lines so as to fit them better than that corresponding to the above equation. And in the reproductions given of the original photographs, the lines are heavy and not parallel and do not seem capable of more accurate measurement.

In the case of helium, the separations for lines polarized parallel to the field were consistently found to be greater than for the corresponding lines polarized perpendicularly. If the effect is real, as it seems to be, the constants of the equation would have to be slightly different for the two sets of components.

In the case of lithium, the reduced separations for 38,000 volts agree with the separations for the corresponding lines of helium. When reduced to 28,500 volts they are a quarter less. The measurements are stated by Stark to be less accurate than for helium, so whether the difference is real remains to be proved. At least the relative separations of the different terms of the series are the same.

It should be stated that as regards asymmetry of position and intensity, the corresponding lines of hydrogen and helium apparently do not behave alike. In fact, Stark reports differences in the behavior of lines of the same series. As he suggests, the very complexity of the phenomenon makes it a most promising field in which to search for clues to a knowledge of atomic structure. It may be too soon to find regularities and the agreements noted above may be accidental. But I think not. If not, they suggest that there is something which is common to the atoms of hydrogen and helium, in addition to the presence of electrons in both.

\section{GoRdon S. FULCHER}

WISCONSIN UNIVERSITY, July 11, 1914

3 L. c., p. 997 . 